\title{
The effect of physical activity interventions on development of children with autism spectrum disorder: content-analysis of researches
}

\author{
Bodnar I.R. ${ }^{\mathrm{ABDE}}$, Hamade A.F. ${ }^{\mathrm{CDE}}$ \\ Lviv State University of Physical Culture, Lviv, Ukraine
}

Authors' Contribution: A - Study design; B - Data collection; C - Statistical analysis; D - Manuscript preparation; E - Funds collection.

\begin{abstract}
Purpose:

Heeding the experience of existing research will allow designing future scientific research. This will increase physical activity (PA), improve physical fitness, maintenance and improvement of health of children with autism spectrum disorders (ASD); assist implementation of inclusion in the educational institutions of the country. Purpose - to analyze the content of physical education programs used in attracting children with autism spectrum disorder to physical activity and to find out domains of indicators that should be investigated.

Material: $\quad$ The analysis of scientific articles for 2000-2019 years was done, 48 publications were selected. The search of documents was carried out in different databases using keywords "autism», «ASD», "physical activity», «fitness». Articles that studied the effect of different means (lesson programs) on the performance of children with ASD were chosen. More than 100 English-language papers for the last 20 years were analyzed. A systematic search for scientific data was conducted, articles that were not related to physical activity were not taken into consideration. The search depth was 3 generations. A content analysis of received data was conducted. The reliability of the differences between the frequency of study of aggregates of indicators was clarified using $x$-test.

Results: $\quad$ Scientists, studying the impact of programs of PA on children with ASD, often focus on disruptive behavioral models (31\%) of these children and on their indicators of physical fitness and motor skills (35\%). Most studies analize the effects of a program using one type of PA.

Conclusions: $\quad$ Among the existing research, there is a lack of multidimensional and multimodal programs that would combine effective means of PA. The frequency of communication and cognitive performance research $(12 \%$ and $10 \%$ respectively) significantly $(p<0.05)$ lags behind the research of frequency of physical and behavioral indicators in children with ASD ( $35 \%$ and $31 \%$ respectively). there is a lack of research that would study different groups of indicators (physical, cognitive and indicators of problem areas of children with ASD, behavioral and communicative) together.

Keywords: physical education, physical activity, psychophysical development, mental development, inclusion, autism, autistic spectrum disorders.
\end{abstract}

\section{Introduction}

Many teachers have difficulties in teaching children with autistic spectrum disorder (ASD) in inclusive classrooms. Some teachers of Physical Education (PE) believe that it is very difficult (even impossible) to teach students with special needs with students without ASD. In recent years, more and more children with ASD have been getting into the environment of educational institutions. This is due to the general trend of increasing number of such children worldwide, and in Ukraine in particular, as well as opening school doors to these children through inclusive schools, which are developing in our country.

Children with ASD have more health problems, in particular higher rates of obesity and metabolic diseases [1]. Also, health conditions that are caused or exacerbated by obesity are inherent for them [2, 3], for example, diabetes, high cholesterol level, and high blood pressure. They have a higher risk of comorbidities $[4,5]$. They are weaker than their peers. These children often suffer from allergies, are vulnerable to a common cold, weather changes [5, 6]. Typical for them are hyperactivity [7],

(c) Bodnar I.R., Hamade A.F., 2019

doi:10.15561/18189172.2019.0302 insomnia $[8,9]$.

Children with ASD typically have suboptimal level of physical activity [10], resulting in more than twice more likely to be obese than other children [11, 12]. Impairments in physical development [13] often leads to disharmony of motor abilities [14, 15]. Children with ASD have delayed formation of gross and fine motor skills, as well as necessary domestic skills [16].

Regular physical activity is important for maintaining a healthy weight and prevent diseases, it is one of the most powerful means of improving the physical fitness of all children, including persons with special needs. Physical education has a great positive impact on children's mental and emotional state, helps raise awareness, attention and ability to concentrate. Exercise affects emotional and volitional spheres, gives the opportunity to find new friends to actively spend time outdoors. Physical activity (PA) is strong incentive not only for psychomotor but also cognitive and emotional development of all students. Most of the studies reporting positive effects of exercise are related to healthy children. At the same time exercise can be especially beneficial for people with disorders in health conditions [17]. 
It is known that physical exercise [18, 19], dancing, outdoor games and sports activities (darts [20], pinball [21], frisbee [22], croquet [23] and bowling [24]), board games and entertainment (UNO [23] and LEGO [25]) have multiply benefits for children with ASD. PA can considerably alleviate the numerous behavioral problems of these children, improve indicators of social interaction and communication, cognitive processes, enhance the physical fitness, formation of motor skills, and quality of life in general. Among the meta-studies there are several which analyzed the level of PA [26], examined effects of various means on PA on cognitive performance and stereotyped behavior $[27,28,29,30]$ of children with ASD. There is evidence of comprehensive research that is only planned to be conducted [31, 32]. However, some issues remain unclarified, for example, which groups of indicators of children with ASD are most often to be studied, and which require deeper analysis in terms of the PA, which PA types are useful to combine in a single lesson or series of lessons. This prevents justifying the organizational and methodological provisions of rational PA for children with ASD.

Heeding the experience of existing research will allow designing future scientific research. This will increase PA, improve physical fitness, maintenance and improvement of health of children with ASD; assist implementation of inclusion in the educational institutions of the country.

The goal of this study was to analyze the content of physical education programs that are used when children with autistic spectrum disorder are attracted to physical activity and to clarify the domain of indicators that should be investigated.

\section{Materials and methods.}

Participants and setting: Having analyzed 2000-2019 research papers, which examined the effect of PA on children with ASD, we selected 48 publications.

Research design. The systematic search of the literature was conducted. Search depth was 3 generations. Articles that were not related to physical activity were not taken into consideration.

Data collection. The search of documents was carried out in different databases using keywords «autism» or «ASD» and "physical activity» or «fitness», and search connectors like «AND», «OR» and «NOT». We chose articles that studied the effect of different means (lesson programs) on the performance of children with ASD on three levels: the title, abstract and table of content. Articles that we selected to analyze at the level of content were used to search for links to checklists of articles that may have been missed during the search in the database. Also, we performed a direct Google search of articles that quoted chosen articles. More than 100 English-language papers for the last 20 years have been analyzed.

Data analysis. A content analysis of received data was conducted. The reliability of the differences between the frequency of study of aggregates of indicators was clarified using $\chi$-test.

\section{Results}

The results show that among the means of PE for children with ASD mostly the efficacy of exercise in water (hydrotherapy, swimming), or run/walk (outdoors or on a simulator) was examined [33, 34, 35, 36, 37, 38, 39]. However, the substantial number of studies have shown benefits of hippotherapy [40, 41, 42, 43] and training of Kata technique in Eastern martial arts [18, 44, 45]. Also a positive effect of rarely used PA means was showed, such us, for example, simulation of riding a horse (on the simulator) [46] or riding a pony (equitherapy) [47], skateboarding [48] or exergaming [49] as well as learning Greek dances [50]. Scientists have proven positive impact of Taekwondo classes [51], gymnastic exercises [52], fitness [53], tennis [54] and table tennis [55]. Thus, the synthesis of the data showed that most researchers are studying the impact of programs using one type of PA. Only a few of them were devoted to reviewing the effectiveness of interventional programs with complex use of means. For example, relaxation exercises with the means of dance and music therapy [56], a program of mixed exercises (for example, cycling, with medicine ball) [57], programs with different ball games [58], a program with inclusion of basic coordination and strength exercises [59], a program of structured physical activity with naturally integrated elements of social interaction [60] can be attributed to comprehensive programs. In a number of studies, the efficiency of two different applications, such as muscular strength and cardiorespiratory program [53], yoga and Chinese gymnastics [61], single or triple burden running [62], dance and exercise bike exergaming [49] were compared. Some [63] balanced the effectiveness of classes even of three programs: the author auxiliary cycle therapy, voluntary cycling and total absence of cyclic loads.

In general, as we expected, a set of physical indicators leads among other aggregations (35\%) according to the frequency of studying indicators which belong to it (Table 1). A large number of researchers noted the improvement of physical abilities $[64,65,66]$ and motor skills $[36$, 47, 67] of children with ASD by means of exercise. The indicators of physical fitness and motor skills were investigated in studies that examined the effectiveness of programs of PE or types of PA for children with ASD quite often (14\%). However, we found that a small portion of research $(3 \%)$ were devoted to the study of indicators of PA (average frequency of sessions, the number of caloric expenditure) and the body weight (4\%).

According to the literature, PA helps to reduce cases of problematic [66, 68] and aggressive behavior [56, 64]. Behavioral outcomes of children with ASD occupy second place in the popularity of indicators which are usually studied (31\%). Such adaptive problems like selfharm, failure to maintain eye contact, sensory sensitivity, echolalia, irritability, etc. were often the object of study in studies of children with ASD (17\%). In terms of PA stereotyped movements are studied in $8 \%$ of cases. The impact of PA on secondary symptoms such as hyperactivity, aggression and sudden mood changes (6\%) 
were studied less.

Thus, our analysis shows that scientists, studying the impact of programs of PA on children with ASD, often focus on disruptive behavioral models (31\%) of these children and on their indicators of physical fitness and motor skills (35\%).

The frequency of research of communication indicators for children with ASD significantly $(p<0.05)$ lags behind frequencies of study of two previous groups (physical and behavioral indicators). Experts studied the changes in social interaction skills and social understanding of children with ASD in each sixth case (12\%).

Twentieth part $(11 \%)$ of research was devoted to the study of changes in cognitive skills (4\%) and academic performance $(6 \%)$ of children with ASD, which is explained by the importance of the cognitive performance of children of school age. The change of rates of material, cultural and spiritual human needs and the quality of life of children with ASD under the influence of exercise was rarely studied (4\%).

In $8 \%$ of cases, experts were exploring other indicators such as satisfaction from classes, family relationships, the duration of the game alone, orientation in the water, quality of sleep, stress level, neuropsychological performance, sensor sensitivity, etc.

\section{Discussion}

Today in the field of education and development of children with autism there are still many unresolved issues. One of these issues is to develop an effective PE program aimed at improving physical performance, mental and physical development and physical fitness of students with ASD, to strengthen their health and eliminate deviations. To do this, scientists are studying changes in indicators in terms of the use of different means of PE working with children with different ASD. However, the ideal program has not yet prepared, as evidenced by the lack of tendency to reduce the number of such children.

Our results showed that different comprehensive studies are carried out infrequently because scientists usually study only 1 (2) indicators from one aggregation and only rarely from two aggregations. It makes it impossible to set the relationship between different indicators or sets of indicators and identify leading indicators for their accented development in children with ASD.

Although scientists often did not observe significant differences between the performance of control and experimental groups, they found some important trends to improve performance in the experiment. We consider that the formation of a comprehensive program using potentially effective combined types of PA may provide greater overall positive effect than the use of one type of PA. Children may not like certain types of PA, others cannot be implemented without the expensive special equipment (for example, horses or swimming pools). Therefore, it is worth continuing to explore the possibilities of PE integrated programs that combine the attractive but available exercise of different types of PA to eliminate the problems of children with ASD.

We first discovered that traditional experimental programs include studying the influence of only one type of PA on indicators of children with ASD. Our results confirmed the data of experts $[26,43]$ about the increased interest of scientists to hydrotherapy and different cyclic movements on land. However, we draw attention to the fact that today there is a significant number of researchers who proved the effectiveness of the use of hippotherapy

Table 1. The frequency of study of parameters during the study of the effectiveness of means in physical education of children with autistic spectrum disorders $(\mathrm{N}=48)$

\begin{tabular}{|c|c|c|c|c|}
\hline The set of indicators & Indexes & $\mathbf{N} *$ & $\%$ & \\
\hline \multirow{4}{*}{ Physical } & physical fitness & 16 & 14 & \multirow{4}{*}{35} \\
\hline & motor skills & 16 & 14 & \\
\hline & weight & 4 & 4 & \\
\hline & physical activity & 3 & 3 & \\
\hline \multirow{3}{*}{ Behavioral } & disadaptation & 20 & 17 & \multirow{3}{*}{31} \\
\hline & stereotype & 9 & 8 & \\
\hline & hyperactivity, aggression & 7 & 6 & \\
\hline Communication & social understanding & 14 & 12 & $12 * *$ \\
\hline \multirow{2}{*}{ Educational } & academic performance & 7 & 6 & \multirow{2}{*}{10} \\
\hline & cognitive characteristics (attention, memory) & 4 & 4 & \\
\hline Quality of life & domains of quality of life & 4 & 4 & 4 \\
\hline other & $\begin{array}{l}\text { pleasure from classes, orientation in the water, } \\
\text { quality of sleep, neuropsychological performance, } \\
\text { sensory sensitivity, etc. }\end{array}$ & 10 & 8 & 8 \\
\hline TOGETHER & - & 83 & $100 \%$ & \\
\hline
\end{tabular}

Notes: 1) * N - number of scientific papers which analyzed these figures in their content; 2 ) $* *$ - reliability of aggregation of indicator differences from the previous figures $-p<0.05$ 
and equitherapy and simulate riding $[40,41,43,46$, 47] and Eastern martial arts [18, 44, 45, 51] in solving problems of children with ASD. Therefore, these tools deserve to be widely used in applications of PE working with children with ASD.

It is socially important in working with this group of children to overcome the major symptoms such as disruptive social behavior, repetitive patterns of activity or stereotyped behavior. However, these figures are not often studied by researchers in the context of the varieties PA efficiency (31\%). In studies of PE industry experts focus on the effects of improving the physical condition $(35 \%)$ of children with ASD. However, changes in some parameters of this group, such as the PA volume and body weight are rarely studied (3\% and $4 \%$ respectively) $[55,55$, 69]. Change in the PA (apart from several other indicators) in children with ASD in the experimental conditions has been studied, for example in the investigation of efficacy of PA outdoors (running or skiing for 30 minutes) for 6 months, this study was based on three people at the age of 15,16 and 20 [ 70], there were other programs like walking on the treadmill for 9 months [69] and playing table tennis for 2 weeks for people aged 8-10 [55]. The growth of a normal body weight in children with ASD has also been noted by a small number of sources in the field of PE (4\%) [55, 59, 69, 71], although the problem of overweight in children with ASD is well known from publications of medical direction $[72,73,74]$. The values of body weight have been measured by the specialists in the study of the effectiveness of walking on a treadmill [69], PE program with priority use of table tennis [55] and programs which include basic coordination and strength exercises [59].

Individual data available in the literature of PE industry about the weight of children with ASD are often contradictory. Some experts [32] reported on lagging behind age norms of muscle in children with ASD as a result of suboptimal amounts of PA and small volumes of PA which was higher than the average intensity. Other experts [75] argued that children with ASD were more vulnerable to overweight and obesity because of less time spent on PA and more time spent on sedentary behavior compared to their peers with common development. Some studies have shown that by comparing PA levels between children with and without ASD [76] there were no significant difference. Contradictory and partial data encourage conducting research dedicated to studying changes in AS volumes of different intensity in children with ASD and related amounts of healthy body weight. If possible, we should try to form healthy behavior patterns in children with ASD associated with regular optimal volume and intensity of PA sessions.

All the children with ASD, regardless of the severity of the ASD, level IQ, or their gender [77], had the significantly lower level of PA than their peers with normal development. Children with ASD took part in sports activities less than other children [78]. The low volumes of PA in children of older school age and adolescents are of particular concern [79]. The intensity of PA in children with ASD lagged behind as well as the volume of PA: they rarely performed vigorous exercise, compared with children without disabilities [31]. Thus, the average time spent on PA of intermediate and upper intermediate level of intensity after school was 17 minutes for the youngest group and 10 minutes for the older age group. Unfortunately, only a very small part of the time was spent in vigorous PA (about one minute for both age groups) [31].

Reduced competence in team games and amusements can limit PA of children with ASD because of problems with sensory processing (from $42 \%$ to $100 \%$ of children with ASD according to different data) [80], the inability to perform complex motor actions due to poor motor skills, problems with coordination of movements and balance [80] and the deficit of social interaction and communication [32]. Limited amount and intensity of PA in patients with ASD can be caused by disturbances in behavior, motor, sensory, social and communication areas. According to our data, the first groups of indicators often became a subject of study sessions under the influence of PE. But in research over the past 20 years, scientists have not paid attention to the formation of verbal skills in children with ASD by means of PE (12\%). Different evidence that the joint PA solves the problem of autistic communication, increases the possibility of friendship in a natural setting is present $[33,42,44]$. However, there is information that individual motor tasks contribute to the formation of social interaction of children with ASD better than group ones [29]. This information is preliminary, and its validity should be checked.

Studies have shown a positive effect of PA on academic activity and academic performance $[39,81,82]$ of people with ASD, as well as improving their cognitive function $[60,68]$. It was found that every 10 th research is devoted to the issues of cognitive skills under the influence of exercise. Thus, it was found that the frequency of research of communication and cognitive performance (12\% and $10 \%$ respectively) under PA significantly $(\mathrm{p}<0.05)$ lags behind the research of frequency of physical and behavioral indicators in children with ASD $35 \%$ and $31 \%$ respectively).

Children with ASD showed suboptimal levels of PA, poor motor skills and physical health [2,6]. Because of that researchers observed the reduced quality of life of the children and their families [83]. Scientists rarely find out (4\%) what is the effect of regular exercise on quality of life of children with autism $[84,85,86]$. Changes that occur in the domains of quality of life of children with ASD under the influence of exercise, the relationship of these indicators with other indicators, as well as differences between individuals with ASD of all ages have not been studied.

Although the volume of literature on PA how to improve physical fitness in patients with ASD is significant, there are problems with the research of evidence base. Due to the inclusion of non-randomized studies, there is a high risk of researchers' bias. Therefore, further study is required to understand better the extent of the benefits that 
these individuals can get during PE.

Received information by us will allow implementing effective programs of classes.

\section{Conclusions}

1. Studies on finding effective means of PE for children with ASD are valid. PA is able to affect positively the problems of children with ASD in psychomotor, cognitive, behavioral, emotional and communicative spheres in a relatively short time.

2. The frequent study of the effectiveness of hydrotherapy, running, walking, hippotherapy and Eastern martial arts in solving problems of children with ASD has been noted. Our results showed that scientists usually study only 1 (2) indicators from one aggregation and only rarely from two aggregations, while there is little complex research. Among the existing research, there is a lack of multidimensional and multimodal programs that would combine effective means of PA.
3. The frequency of communication and cognitive performance research $(12 \%$ and $10 \%$ respectively) significantly $(\mathrm{p}<0.05)$ lags behind the research of frequency of physical and behavioral indicators in children with ASD (35\% and $31 \%$ respectively). Data on changing the quality of life (4\%), the volume of PA (3\%) and body weight $(4 \%)$ of children with ASD are sporadic and inconsistent. However, there is a lack of research that would study different groups of indicators (physical, cognitive and indicators of problem areas of children with ASD, behavioral and communicative) together. This prevents from finding out the leading figures of them for accented development.

\section{Conflict of interest}

The authors declare that there is no conflict of interest.

\section{References}

1. Nikolov RN, Bearss KE, Lettinga J, Erickson C, Rodowski M, Aman MG, McCracken JT, McDougle CJ, Tierney E, Vitiello B, Arnold LE, Shah B, Posey DJ, Ritz L, Scahill L. Gastrointestinal symptoms in a sample of children with pervasive developmental disorders. J Autism Dev Disord., 2009; 39(3):405-413. https://doi.org/10.1007/s10803-008-0637-8

2. Balogun F. Prevalence and Correlates of Obesity in Childhood Autism Spectrum Disorders: A Literature Review. Journal of Psychiatry, 2016;19. https://doi.org/10.4172/2378-5756.1000385

3. Zuckerman KE, Hill AP, Guion K, Voltolina L, Fombonne E. Overweight and obesity: prevalence and correlates in a large clinical sample of children with autism spectrum disorder. J Autism Dev Disord, 2014; 44(7):1708-19. https://doi.org/10.1007/s10803-014-2050-9

4. Al Backer NB. Correlation between autism treatment evaluation checklist (ATEC) and childhood autism rating scale (CARS) in the evaluation of autism spectrum disorder. Sudan J Paediatr., 2016; 16(1):17-22.

5. Schieve LA, GonzalezV, Boulet SL, Visser SN, RiceCE, Braun KVN, Boyle, CA. Concurrent medical conditions and health care use and needs among children with learning and behavioral developmental disabilities, National Health Interview Survey, 2006-2010. Res Dev Disabil., 2012; 33(2):467-476. https://doi.org/10.1016/j.ridd.2011.10.008.

6. Atladottir HO, Thorsen P, Schendel DE, Ostergaard L, Lemcke $\mathrm{S}$, Parner ET. Association of hospitalization for infection in childhoodwithdiagnosisofautismspectrumdisorders:aDanish cohort study. Arch Pediatr Adolesc Med., 2010; 164:470-477. https://doi.org/10.1001/archpediatrics.2010.9

7. Green SA, Ben-Sasson A, Soto TW, Carter AS. Anxiety and sensory over-responsivity in toddlers with autism spectrum disorders: bidirectional effects across time. J Autism Dev Disord., 2012 42(6):1112-1119. https://doi.org/10.1007/s10803-011-1361-3

8. Miano S, Ferri R. Epidemiology and management of insomnia in children with autistic spectrum disorders. Pediatr Drugs, 2010; 12(2):75-84. https://doi.org/10.2165/11316140-000000000-00000
9. Smith KRM, Matson JL. Behavior problems: differences among intellectually disabled adults with co-morbid autism spectrum disorders and epilepsy. Res Dev Disabil., 2010; 31(5):1062-1069. https://doi.org/10.1016/j.ridd.2010.04.003

10.Must A, Phillips SM, Curtin C, Anderson SE, Maslin $\mathrm{M}$, Lividini $\mathrm{K}$, et al. Comparison of sedentary behaviors between children with autism spectrum disorders and typically developing children. Autism, 2014; 18(4):376-84. https://doi.org/10.1177/1362361313479039

11.Egan AM, Dreyer ML, Odar CC, Beckwith M, Garrison CB. Obesity in young children with autism spectrum disorders: prevalence and associated factors. Child Obes., 2013; 9(2):125-131. https://doi.org/10.1089/chi.2012.0028

12.Phillips KL, Schieve LA, Visser S, Boulet S, Sharma AJ, Kogan MD, Boyle CA, Yeargin-Allsopp M. Prevalence and impact of unhealthy weight in a national sample of US adolescents with autism and other learning and behavioral disabilities. Matern Child Health J., 2014;18(8):1964-1975. https://doi.org/10.1007/s10995-014-1442-y.

13.Jansiewicz EM, Goldberg MC, Newschaffer CJ, Denckla MG, Landa R, \& Mostofsky SH. Motor signs distinguish children with high functioning autism and Asperger's syndrome from controls. Journal of Autism and Developmental Disorders, 2006; 36:613-621. https://doi.org/10.1007/s10803-006-0109-y

14.Ament Katarina, Mejia Amanda, Buhlman Rebecca, Erklin Shannon, Caffo Brian, Mostofsky Stewart, Wodka Ericka. Evidence for Specificity of Motor Impairments in Catching and Balance in Children with Autism J Autism Dev Disord., 2015; 45(3): 742-751. https://doi.org/10.1007/s10803-014-2229-0

15.American Psychological Association. Diagnostic and Statistical Manual of Mental Disorders (5th ed.) (DSM-5). Washington, DC: AP, 2013.

16.Green D, Charman T, Pickles A, Chandler S, Loucas T, Simonoff E, Baird G. Impairment in movement skills of children with autistic spectrum disorders. Dev Med Child Neurol., 2009;51(4):311-6. https://doi.org/10.1111/j.1469-8749.2008.03242.x

17.Bodnar Ivanna, Shevtsiv Uliana. Influence of Integrative 
Physical Education on Physical Preparedness of Schoolchildren with Different Levels of Functional and Reserve Capabilities. Naukovyi chasopys. 2017; 15(86):38 41. (in Ukrainian)

18.Bahrami F, Movahedi A, Marandi SM, Abedi A. Kata techniques training consistently decreases stereotypy in children with autism spectrum disorder. Research in Developmental Disabilities, 2012; 33: 1183-1193. https://doi.org/10.1016/j.ridd.2012.01.018.

19.Pan CY. Effects of water exercise swimming program on aquatic skills and social behaviors in children with autism spectrum disorders. Autism, 2010;14(1):9-28. https://doi.org/10.1177/1362361309339496.

20.Schleien SJ, Kiernan J, Wehman, P. Evaluation of an ageappropriate leisure skills program for moderately retarded adults. Education and Training of the Mentally Retarded, 1981; 16: 13-19.

21.Hill JW, Wehman P, \& Horst G. Toward generalization of appropriate leisure and social behavior in severely handicapped youth: Pinball machine use. The Journal of the Association for the Severely Handicapped, 1982; 6:38-44. https://doi.org/10.1177/154079698200600406

22.Horst G, Wehman P, Hill JW, \& Bailey C. Developing age-appropriate leisure skills in severely handicapped adolescents. Teaching Exceptional Children, 1981; 14:11-15. https://doi.org/10.1177/004005998101400102

23.Wall ME., Gast DL. Caregivers' use of constant time delay to teach leisure skills to adolescent or young adults with moderate or severe intellectual disabilities. Education and Training in Mental Retardation and Developmental Disabilities, 1997; 32: 340-356.

24.Zhang J, Bridget C, Shihui C, John, L. The effect of a constant time delay procedure on teaching an adult with severe mental retardation a recreation bowling skill. The Physical Educator, 2004; 61: 63-74.

25.Lindsay S, Hounsell KG, Cassiani C. A scoping review of the role of LEGO ${ }^{\circledR}$ therapy for improving inclusion and social skills among children and youth with autism. Disabil Health J., 2017 10(2):173-182. https://doi.org/10.1016/j.dhjo.2016.10.010

26.Downey R, Rapport MJK. Motor activity in children with autism: a review of current literature. Pediatr Phys Ther., 2012; 24(1):2-20. https://doi.org/10.1097/PEP.0b013e31823db95f

27.Healy S, Nacario A, Braithwaite RE, Hopper C. The effect of physical activity interventions on youth with autism spectrum disorder: A meta-analysis. Autism Res., 2018;11(6):818-833. https://doi.org/10.1002/aur.1955

28.Petrus C, Adamson SR, Block L, Einarson SJ, Sharif Nejad M, Harris SR. Effects of exercise interventions on stereotypic behaviours in children with autism spectrum disorder. Physiother Can, 2008; 60(2):134-145. https://doi.org/10.3138/physio.60.2.134

29.Sowa M, Meulenbroek R. Effects of physical exercise on autism spectrum disorders: a meta-analysis. Res Autism Spectr Disord, 2012; 6(1):46-57.

30.Tan BW, Pooley JA, Speelman CP. A Meta-Analytic Review of the Efficacy of Physical Exercise Interventions on Cognition in Individuals with Autism Spectrum Disorder and ADHD. J Autism Dev Disord., 2016;46(9):3126-43. https://doi.org/10.1007/s10803-016-2854-x

31.MacDonald M., Esposito Ph., Ulrich D. The physical activity patterns of children with autism. BMCRes Notes., 2011; 4: 422. https://doi.org/10.1186/1756-0500-4-422

32. Yu CCW, Wong SWL, Lo FSF, So RCH, Chan DFY. Study protocol: a randomized controlled trial study on the effect of a game-based exercise training program on promoting physical fitness and mental health in children with autism spectrum disorder. BMC Psychiatry. 2018: 27;18(1):56. https://doi.org/10.1186/s12888-018-1635-9

33.Bumin G, Uyanik M, Yilmaz I, Kayihan H, Topcu M. Hydrotherapy for Rett Syndrome. J. Rehabil. Med. 2002; 34: $1-2$.

34.Fragala-Pinkham MA, Haley SM, O'Neil ME. Group swimming and aquatic exercise programme for children with autism spectrum disorders: a pilot study. Dev Neurorehabil., 2011; 14(4):230-241. https://doi.org/10.3109/17518423.2011.575438

35.Pan CY. The efficacy of an aquatic program on physical fitness and aquatic skills in children with and without autism spectrum disorders. Research in Autism Spectrum Disorders, 2011; 5: 657-665.

36.Rogers L, Hemmeter ML, Wolery M. Using a constant time delay procedure to teach foundational swimming skills to children with autism. Topics Early Childhood Special Educ. 2010; 30(2): 102-111. https://doi.org/10.1177/0271121410369708

37. Yanardag M, Akmanoglu N, Yilmaz I. The effectiveness of video prompting on teaching aquatic play skills for children with autism. Disabil Rehabil. 2013;35(1):47-56.

38. Yilmaz I, Yanardag M, Birkan B A., Bumin, G. Effects of swimming training on physical fitness and water orientation in autism. Pediatrics International, 2004; 46, 624-626.

39. Oriel KN, George CL, Peckus R, Semon A. The effects of aerobic exercise on academic engagement in young children with autism spectrum disorder. Pediatr Phys Ther., 2011; 23(2):187-193. https://doi.org/10.1097/PEP.0b013e318218f149

40.Bass MM, Duchowny CA, Llabre MM. The effect of therapeutic horseback riding on social functioning in children with autism. Journal of Autism and Developmental Disorders. 2009; 39(9):1261-1271.

41.Gabriels RL, Pan Z, Dechant B, Agnew JA, Brim N, Mesibov G. Randomized controlled trial of therapeutic horseback riding in children and adolescents with autism spectrum disorder. J Am Acad Child Adolesc Psychiatry, 2015; 54(7):541-549. https://doi.org/10.1016/j.jaac.2015.04.007.

42.Gabriels, R. L., Agnew, J. A., Holt, K. D., Shoffner, A., Pan, Z., Ruzzano, S., et al. Pilot study measuring the effects of therapeutic horseback riding on school-age children and adolescents with autism spectrum disorders. Research in Autism Spectrum Disorders, 2012; 6: 578-588. https://doi.org/10.1016/j.rasd.2011.09.007

43. Hawkins BL, Ryan JB, Cory AL, Donaldson MC. Effects of equine-assisted therapy on gross motor skills of two children with autism spectrum disorder: A single-subject research study. Therapeut. Recreat. J., 2014; 48(2):135-149.

44.Bahrami F, Movahedi A, Marandi SM, Sorensen C. The effect of karate techniques training on communication deficit of children with autism spectrum disorders. J Autism Dev Disord., 2016; 46(3):978-86. https://doi.org/10.1007/s10803-015-2643-y

45.Movahedi A, Bahrami F, Marandi M, Abedi A. Improvement in social dysfunction of children with autism spectrum disorder following long term Kata techniques training. Research in Autism Spectrum Disorders, 2013; 7: 1054-1061. https://doi.org/10.1016/j.rasd.2013.04.012

46. Wuang YP, Wang CC, Huang MH, Su CY. The effectiveness of simulated developmental horse-riding program in children with autism. Adapt Phys Activ Q., 2010;27:113-126.

47.Hameury L, Delavou P, Teste B, Leroy C, Gaboriau J.-C, $\&$ Berthier A. Équithérapie et autisme. Annales Médico- 
Psychologiques, 2010; 168, 655-659.

48.Thomas, B.R., Lafasakis, M. \& Spector, V. J Brief Report: Using Behavioral Skills Training to Teach Skateboarding Skills to a Child with Autism Spectrum Disorder. Autism Dev Disord, 2016; 46: 3824. https://doi.org/10.1007/s10803-016-2900-8

49.Anderson-Hanley, C., Tureck, K., \& Schneiderman, R. L. Autism and exergaming: effects on repetitive behaviors and cognition. Psychology Research and Behavior Management, 2011; 4: 129-137. https://doi.org/10.2147/PRBM.S24016

50.Arzoglou D, Tsimaras V, Kotsikas G, Fotiadou E, Sidiropoulou M, Proios M, et al. The effect of a traditional dance training program on neuromuscular coordination of individuals with autism. JPES, 2013;13(4):563-569. https://doi.org/10.7752/jpes.2013.04088

51.Kim Y, Todd T, Fujii T, Lim JC, Vrongistinos K, Jung T. Effects of Taekwondo intervention on balance in children with autism spectrum disorder. J Exerc Rehabil. 2016; 12(4): 314-319. https://doi.org/10.12965/jer.1632634.317

52.Zamani JA, Talab RH., Sheikh M. et al. The effect of 16 weeks gymnastic training on social skills and neuropsychiatric functions of autistic children. Sport Sci Health, 2018; 14: 215. https://doi.org/10.1007/s11332-018-0436-3

53.Lochbaum M, Crews D. Viability of cardiorespiratory and muscular strength programs for the adolescent with autism. Complement Health Pract Rev. 2003;8:225-233. https://doi.org/10.1177/1076167503252917

54.Yanardağ M, Birkan B, Y1lmaz İ, Konukman F, Ağbuğa B, Lieberman L. The effects of least-to-most prompting procedure in teaching basic tennis skills to children with autism Kinesiology, 2011; 1:44-55.

55.Pan CY, Chu CH, Tsai CL, Sung MC, Huang CY, Ma WY. The impacts of physical activity intervention on physical and cognitive outcomes in children with autism spectrum disorder. Autism, 2017;21(2):190-202. https://doi.org/10.1177/1362361316633562

56.Rosenblatt LE, Gorantla S, Torres JA, Yarmush RS, Rao S, et al. Relaxation response-based yoga improves functioning in young children with autism: a pilot study. J Altern Complement Med , 2011; 17: 1029-1035. https://doi.org/10.1089/acm.2010.0834

57. Morrison H, Roscoe EM, Atwell A. An evaluation of antecedent exercise on behavior maintained by automatic reinforcement using a three-component multiple schedule. J Appl Behav Anal, 2011; 44(3):523-541. https://doi.org/10.1901/jaba.2011.44-523

58.Rafie F, Ghasemi A, Zamani JA, Jalali S. Effect of exercise intervention on the perceptual-motor skills in adolescents with autism. J Sports Med Phys Fitness., 2017; 57(1-2): 53-59. https://doi.org/10.23736/S0022-4707.16.05919-3

59. Toscano CVA, Carvalho HM, Ferreira JP. Exercise effects for children with autism spectrum disorder: metabolic health, autistic traits, and quality of life. Percept Mot Skills., 2018;125(1):126-146. https://doi.org/10.1177/0031512517743823

60.Zhao M, Chen Sh. The Effects of Structured Physical Activity Program on Social Interaction and Communication for Children with Autism BioMed Research International, 2018, Article ID 1825046.

61.Chan AS., Sze SL., Siu NY., Lau EM., Cheung MC. A Chinese mind-body exercise improves self-control of children with autism: a randomized controlled trial https. PLoS One., 2013; 10;8(7):e68184. https://doi.org/10.1371/journal.pone.0068184

62.Prupas A, Reid G. Effects of Exercise Frequency on
Stereotypic Behaviors of Children with Developmental Disabilities Education and Training in Mental Retardation and Developmental Disabilities, 2001; 36(2):196-206.

63.Ringenbach S, Lichtsinn K, Holzapfel S. Assisted Cycling Therapy (ACT) improves inhibition in adolescents with autism spectrum disorder. $J$ Intellect Dev Disabil., 2015; 40(4):376-387. https://doi.org/10.3109/13668250.2015.1080352

64.Bumin G, Uyanik M, Yilmaz I, Kayihan H, Topcu M. Hydrotherapy for Rett syndrome. Journal of Rehabilitation Medicine, 2003, 35(1), 44-45. https://doi.org/10.1080/16501970306107

65. Yilmaz I, Ergun N, Konukman F et al. Effects of a 10 week water exercise and swimming program on the physical fitness of mentally retarded children. Res. Quart. Exerc. Sport, 2002; 73 (1): 108-120.

66. Yilmaz I, Yanardad M, Birkan B, Bumin G. Patient report: effects of swimming training on physical fitness and water. Pediatr Int, 2004;46:624-626.

67.Aksay E, Güllü M. Effects of physical activity programs with visual stimuli on physical development of children with autism spectrum disorder. Visual stimuli and movement therapy. Journal of Education and Sociologi, 2014; 5(1): 3443.

68.O'Connor J, French R, Henderson H. Use of physical activity to improve behavior of children with autism-two for one benefits. Palaestra., 2000;16:22-29.

69.Pitetti KH, Rendoff AD, Grover T, Beets MW. The Efficacy of a 9-Month Treadmill Walking Program on the Exercise Capacity and Weight Reduction for Adolescents with Severe Autism. Journal of Autism and Developmental Disorders, 2007, 37(6):997-1006. https://doi.org/10.1007/s10803-006-0238-3

70.Todd T, Reid G . Increasing physical activity in individuals with autism. Focus Autism Other Dev. Disabil. 2006; 21(3):167-176.

71.Neely L, Rispoli M, Gerow S, Ninci J. Effects of antecedent exercise on academic engagement and stereotypy during instruction. Behav Modif, 2014; 39(1):98-116. https://doi.org/10.1177/0145445514552891

72.Castro K, Faccioli LS, Baronio D, Gottfried C, Perry IS, Riesgo R. Feeding behavior and dietary intake of male children and adolescents with autism spectrum disorder: A case-control study. Int J Dev Neurosci., 2016;53:68-74. https://doi.org/10.1016/j.ijdevneu.2016.07.003.

73.Marí-Bauset S, Llopis-González A, Zazpe I, Marí-Sanchis A, Morales Suárez-Varela M. Comparison of nutritional status between children with autism spectrum disorder and typically developing children in the Mediterranean Region (Valencia, Spain). Autism., 2017;21(3):310-322. https://doi.org/10.1177/1362361316636976

74.Shmaya Y, Eilat-Adar S, LeitnerY, Reif S, Gabis L. Nutritional deficiencies and overweight prevalence among children with autism spectrum disorder. Res Dev Disabil., 2015; 38:1-6. https://doi.org/10.1016/j.ridd.2014.11.020

75.Pan C-Y. Objectively measured physical activity between children with autism spectrum disorders and children without disabilities during inclusive recess settings in Taiwan. J Autism Dev Disord, 2008; 38(7):1292-1301. https://doi.org/10.1007/s10803-007-0518-6

76.Sandt DDR, Frey GC. Comparison of physical activity levels between children with and without autistic spectrum disorders. Adapt Phys Act Q., 2005; 22: 146-159.

77.MacDonald M., Esposito Ph., Ulrich D. The physical activity patterns of children with autism. BMCRes Notes., 2011; 4: 422. https://doi.org/10.1186/1756-0500-4-422 
78.Bandini LG, Gleason J, Curtin C, Lividini K, Anderson SE, Cermak SA, Maslin M, Must A. Comparison of physical activity between children with autism spectrum disorders and typically developing children. Autism. 2013;17(1):44-54. https://doi.org/10.1177/1362361312437416

79.Memari AH, Kordi R, Ziaee V, Sotoodeh MS. Weight status in Iranian children with autism spectrum disorders: Investigation of underweight, overweight and obesity, Research in Autism Spectrum Disorders 2012; 6(1). 45-53. https://doi.org/10.1016/j.rasd.2011.05.004

80. Reynolds S, Bendixen RM, Lawrence T, Lane SJ. A pilot study examining activity participation, sensory responsiveness, and competence in children with high functioning autism spectrum disorder. J Autism Dev Disord., 2011;41:14961506.

81.Hartshorn K, Olds L, Field T, Delage J, Cullen C, \& Escalona A. Creative movement therapy benefits children with autism. Early Child Development and Care, 2001;166(1):1-5. https://doi.org/10.1080/0300443011660101
82.Nicholson HK, Bray TJ, Heest MA, Van J. The effects of antecedent physical activity on the academic engagement of children with autism spectrum disorder. Psychol Schools., 2011;48:198-213. https://doi.org/10.1002/pits.20537

83.Matson JL, Goldin RL. Comorbidity and autism: trends, topics and future directions. Res Autism Spectr Disord., 2013; 7(10):1228-1233. https://doi.org/10.1016/j.rasd.2013.07.003

84.Baghdadli A, Pry R, Michelon C, Rattaz C. Impact of autism in adolescents on parental quality of life. Qual Life Res., 2014; 23(6):1859-1868. https://doi.org/10.1007/s11136-014-0635-6

85.Ennis E. The effects of a physical therapy-directed aquatic program on children with autism pectrum disorders. Journal of Aquatic Physical Therapy., 2011;19(1):4-10.

86.García-Villamisar DA, Dattilo J. Effects of a leisure programme on quality of life and stress of individuals with ASD. J Intellect Disabil Res., 2010; 54(7):611-619. https://doi.org/10.1111/j.1365-2788.2010.01289.x

\section{Information about the authors:}

Bodnar I.R.: (Corresponding author) ; http://orcid.org/0000-0002-7083-6271: ivannabodnar@ukr.net: Lviv State University of Physical Culture named after Ivan Bobersky: st. T.Kostiushky, 11, Lviv, 79000, Ukraine.

Hamade A.F.: http://orcid.org/0000-0002-6037-4333: oli2342003@yahoo.com: Lviv State University of Physical Culture named after Ivan Bobersky: st. T.Kostiushky, 11, Lviv, 79000, Ukraine..

Cite this article as:

Bodnar IR, Hamade AF. The effect of physical activity interventions on development of children with autism spectrum disorder. content-analysis of researches. Pedagogics, psychology, medical-biological problems of physical training and sports, 2019;23(3):118-125.

https://doi.org/10.15561/18189172.2019.0302

This is an Open Access article distributed under the terms of the Creative Commons Attribution License, which permits unrestricted use, distribution, and reproduction in any medium, provided the original work is properly cited (http://creativecommons.org/licenses/by/4.0/deed.en).

Received: 03.04.2019

Accepted: 25.04.2019; Published: 29.06.2019 